\title{
Effects of Ascaris suum Extract and Sulfamethoxazole on Allergic Airway Inflammation
}

\author{
Eun-Sang Cho', Bae-Keun Park and Hwa-Young Son ${ }^{2, *}$ \\ ${ }^{1}$ College of Veterinary Medicine, ${ }^{2}$ College of Veterinary Medicine \& Graduate School of New Drug Discovery and Development, \\ Chungnam National University, Daejeon 305-764, Republic of Korea
}

\begin{abstract}
Allergic asthma is complex inflammatory airway disorder caused by genetic and environmental factors. Sulfamethoxazole, a sulfonamide, is the cause of drug rash with eosinophilia and systemic symptoms syndrome. Parasites infection also related with eosinophilia and allergic diseases. In the present study, we investigated the modulating effects of parasitic derivative and sulfamethoxazole (SMX) on allergic airway inflammation in the ovalbumin (OVA)-induced murine asthma model. Histopathological changes, cytokine secretion, and total and allergen-specific IgE were investigated. BALB/c mice were treated with Ascaris suum extract or SMX for 4 weeks before sensitized and challenged to ovalbumin. Pre-treatment of Ascaris suum extract decreased allergic inflammation in lung tissue and IL-4, total IgE, and OVA-specific IgE levels in bronchoalveolar lavage fluid. However, pre-treatment of SMX did not show any effects on allergic airway inflammation. These results indicate that parasitic infection has protective effects on allergic asthma, but the sulfamamides may not relate with allergic asthma.
\end{abstract}

Key Words: Asthma, Ascaris. suum, Sulfamethoxazole, Ovalbumin, Eosinophilia

\section{INTRODUCTION}

Allergic asthma is a chronic inflammatory disease, characterized by variable degree of airflow obstruction, airway eosinophillic inflammation, bronchial hyperresponsiveness, mucus hypersecretion, and increase of serum IgE level (Elias et al., 1999). An airway inflammation in allergic asthma is associated with the infiltration of diverse leukocyte, and increased numbers of these cells have been found in the broncho-alveolar lavage (BAL) fluid (Kay, 1991). Eosinophils and lymphocytes, the most common cells, migrate from the peripheral circulation to the bronchial and bronchiolar spaces, and accumulate in the lung. Allergic disorders associated with genetic element (Hoffjan and Ober, 2002), and environmental factors. Incidence of asthma in Western Europe has increased compared to Eastern Europe (Matricardi, 2001). There is a considerably lower prevalence of allergic diseases in developing countries, and children raised in suburban have lower incidences of asthma compared to urban settings (Britton 2003; Yemaneberhan et al., 1997). In addition, modulation of allergy by infections, such as mycobacteria, adenovirus, and helminth has been documented. Epidemiological data showed that allergic asthma has low frequency in people exposed to orofaecal and foodborne microbes (Matricardi et al., 2000). In addition, some

\section{www.biomolther.org}

Open Access http://dx.doi.org/10.4062/biomolther.2011.19.4.466

pISSN: 1976-9148 elSSN: 2005-4483

Copyright $\odot 2011$ The Korean Society of Applied Pharmacology parasites are associated with reduced risk of atopy in children (Lynch et al., 1993; van del Biggelaar et al., 2000).

Drug rash with eosinophilia and systemic symptoms (DRESS) syndrome or drug-induced hypersensitivity syndrome (DIHS) is a drug-induced severe adverse reaction characterized by generalized symptoms such as fever, skin eruptions, lymphadenopathy, hepatic dysfunction, and eosinophilia (Callot et al., 1996). Administration of sulfamethoxazole (SMX), a sulfonamide, is associated with a high incidence of hypersensitivity reactions in human (Mandell and Sande, 1990).

In the present study, the modulating effects of Ascaris suum extract or SMX on accumulation of inflammatory cells into airways, cytokines and antibody production and histopathologic changes was investigated in the OVA-induced murine asthma model.

\section{MATERIALS AND METHODS}

\section{Ascaris suum extract}

A. suum worm extract (ASC) was prepared according to the method with a slight modification as described (Strejan and Campbell, 1967). Briefly, adult $A$. suum were isolated from

Received Jun 15, 2011 Revised Sep 11, 2011 Accepted Sep 23, 2011

\footnotetext{
*Corresponding Author

Email: hyson@cnu.ac.kr

Tel: +82-42-821-6787, Fax: +82-42-821-8903
} 
infected mice, soaked with cold nitrogen and washed several times with buffered saline. The sample was mixed with $10 \mathrm{ml}$ of buffered saline and homogenized in an Ultra-Turrax apparatus (Janke and Kunkel, Staufen, Germany). The homogenate was centrifuged at $10,000 \mathrm{~g}$ for $20 \mathrm{~min}$ twice, the precipitate was re-suspended in buffered saline $(200 \mathrm{ug} / \mathrm{ml})$. This suspension was prepared at $100 \mathrm{ug} / \mathrm{ml}$ in the Freund's adjuvant (Sigmaaldrich, MO, USA).

\section{Animals}

Six weeks old female BALB/c mice were obtained from NARA Biotech (Yongin, Korea) and maintained in specific pathogen-free conditions. The animals were maintained under standard laboratory conditions and provided with water and standard chow (Jeil feed Co., Daejeon, Korea) ad libitum. All experimental procedures were performed in according to the $\mathrm{NIH}$ Guidelines for the care and Use of Laboratory Animals.

\section{Sensitization and airway challenge}

Groups of mice $(n=7)$ received the following treatments: (NC) sham-sensitization and challenge with PBS; (OVA) sensitization and challenge with OVA (Sigma, MO, USA); (AS) A. suum extract treatment plus sensitization and challenge with OVA; (SMX) SMX treatment plus sensitization and challenge with OVA. Briefly, AS and SMX group mice were injected with $20 \mathrm{ug}$ of $A$. suum derivative via intramuscular or SMX (1 mg with 4\% DMSO in PBS) via subcutaneous at intervals of 1 week for 4 weeks. Then, mice were sensitized by intraperitoneal injection of $20 \mathrm{ug}$ OVA and $2 \mathrm{mg}$ aluminum hydroxide (Sigma, MO, USA) or PBS in a total volume of $100 \mathrm{ul}$ on 5 weeks and 6 weeks. Two weeks later, mice were challenged through the airways with OVA (1\% in PBS) or PBS for 20 min on 3 consecutive days by ultrasonic nebulization (NE-U12; Omron Corp., Tokyo, Japan). Animals were euthanized 48 hours after the last challenge.

\section{Bronchoalveolar lavage (BAL) fluid and quantity of in- flammatory cells}

Mice were sacrificed $48 \mathrm{hr}$ after the last challenge, and tracheotomy was performed. BAL was performed three times with $0.7 \mathrm{ml}$ of sterile PBS instilled and harvested gently. BAL fluid was centrifuged, and the supernatant collected and stored at $-70^{\circ} \mathrm{C}$. Pellets were washed three times with PBS, and resuspended in $1.0 \mathrm{ml}$ PBS and $100 \mu \mathrm{l}$ of BAL fluid placed on a slide, and centrifuged $\left(200 \mathrm{~g}, 4^{\circ} \mathrm{C}, 10 \mathrm{~min}\right)$ for fixation using cytospin (Hanil Science Industrial, Seoul, Korea). These cells were fixed and stained using Diff-Quik ${ }^{\circledR}$ stain reagents (Dade Behring Inc., IL, USA) according to the manufacturer's instructions. Total of 200 cells were counted for each sample by microscopy. Macrophages, lymphocytes, neutrophils and eosinophils were quantified.

\section{Pathological analysis}

After lavage, the lung tissues were instilled with $10 \%$ buffered formalin, removed and fixed in the same solution. Tissues were trimmed and embedded in paraffin, cut into 4 um sections for microscopy, and stained with Hematoxylin and Eosin solution (BBC Biochemical, WA, USA) and periodic acid-Schiff (PAS) (BBC Biochemical, WA, USA). An index of pathological changes in H\&E slides was obtained by scoring the inflammatory infiltrates around the airways and vessels for greatest severity $(0$, normal; $1, \leq 3$ cells diameter thick; $2,4-10$ cells diameter thick; $3, \geq 10$ cells diameter thick) and overall extent ( 0 , normal; $1,<25 \%$ of sample; $2,25-50 \%$; $3,51-75 \%$; $4,>75 \%$ ). The index was calculated by multiplying severity by extent (Hamada et al., 2003). A histological goblet cell score was evaluated by examining $10-20$ consecutive airways at $\times 40$ magnification and categorized according to the abundance of PAS-positive goblet cells $(0,<5 \%$ goblet cells; $1,5-25 \% ; 2$, $25-50 \% ; 3,50-75 \% ; 4,>75 \%)$. The index was calculated by dividing the sum of the airway scores from each lung by the number of airways examined for the histological goblet cell score (McMillan et al., 2005).

\section{Assay of total and OVA-specific IgE in BAL fluid}

Total IgE was measured by enzyme-linked immunosorbent assay (ELISA). 96-well microtiter plates (Nunc, MA, USA) were coated with $100 \mathrm{ul} / \mathrm{well} \mathrm{lgE}(2 \mathrm{ug} / \mathrm{ml}$; Serotec, Oxford, UK) and detected with isotype-specific secondary antibodies (1 ug/ml; HRP-conjugated anti-mouse IgE; Serotec, Oxford, UK) followed by addition of BAL fluid. The reaction was developed with o-phenylenediamine dihydrochloride (Sigma, MO, USA) and absorbance was measured at $450 \mathrm{~nm}$. For a standard curve, recombinant lgE were diluted in a series of 8 twofold, starting at $500 \mathrm{ng} / \mathrm{ml}$ (Serotec, Oxford, UK) were used for calculating concentrations.

\section{Th2 cytokines in BAL fluid}

The amount of interleukin-4 (IL-4) involved in BAL fluid was measured by ELISA. For the detection, mouse IL-4 ELISA kits were used according to the manufacturer's instruction (Invitrogen, CA, USA). The detection limit of the kit was $5 \mathrm{pg} / \mathrm{ml}$.

\section{Statistical analysis}

All data in the text and figures is expressed as the mean \pm standard deviations (SD). Statistical significance was determined using Student's two-tailed $t$-test and ANOVA test to compare independent mean values, employing SPSS. The critical level for significance was set at $p<0.05$.

\section{RESULTS}

\section{Total cells and differential cells count in BAL fluid}

As increased total number of cells and accumulation of eosinophils in alveoli are hallmark of allergic asthma, we analyzed cells recruited to the BAL fluid $48 \mathrm{hr}$ after the last challenge. In OVA-challenged mice, OVA challenge induced increases in the numbers of total leukocytes, including macrophages, neutrophils, eosinophils and lymphocytes compared with PBS-challenged mice in the BAL fluid. In contrast, immunizing with $A$. suum extract resulted in significant reductions of the numbers of total inflammatory cells and eosinophils in the BAL fluid compared with those of OVA-challenged mice $(p<0.05)$, but treatment of SMX before OVA sensitization did not affect the level of inflammatory cells (Fig. 1).

\section{Pathological changes of lung}

OVA aerosol-challenged mice showed pathological changes of pulmonary allergic inflammation such as marked infiltration of inflammatory cells involving eosinophils and mononuclear cells into the peribronchiole and perivascular connective tissue. Mice immunized by $A$. suum extract before allergic sensitization with OVA showed a small inflammatory infiltrate 
and diminished pathologic changes in the structural cells of the airways, but SMX pre-treated mice showed similar patterns of pathologic changes in the lung compared with allergic mice (Fig. 2).

Over-production of mucus and goblet cell hyperplasia in the airway were evaluated by PAS staining. PBS-exposed mice showed normal lung histology. In contrast, the number of goblet cells and mucus production were dramatically increased in the epithelium of allergic mice, which was significantly reduced by immunizing with $A$. suum. However, OVA-induced goblet cell hyperplasia and mucus production was not changed by treatment of SMX (Fig. 3). The result of quantitative analysis of histopathology support the changes described above (Fig. 4).

\section{Circulating total and allergen-specific IgE and Th2 cyto- kine}

Allergy is characterized by high levels of allergen-specific $\operatorname{lgE}$ and Th2 cytokines. Thus we examined the effects of $A$. suum extract or SMX immunizing on allergen-specific immune responses in BAL fluid. Allergic sensitization resulted in high levels of total and OVA-specific IgE.

Immunizing with $A$. suum before OVA sensitization significantly decreased the levels IgE antibodies compared with OVA treated mice. SMX pre-treatment slightly decreased total and OVA-specific IgE level without statistical significance. Allergic mice showed higher level of IL-4 compared with control

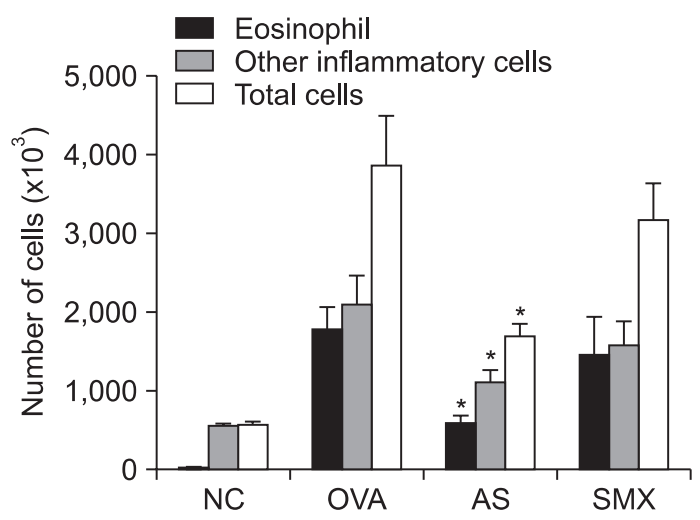

Fig. 1. Total and different cells count in BAL fluid. Pre-treatment of A. suum extract before OVA-sensitization diminished the number of inflammatory cells significantly compared with OVA group in bronchoalveolar lavage (BAL) fluid. But SMX pre-treatment did not show significant changes. NC: sham-sensitization and challenge with PBS, OVA: OVA-sensitization and challenge mice, AS: A. suum extract treatment plus sensitization and challenge with OVA, SMX: Sulfamethoxazole (SMX) pre-treated plus OVA-sensitization and challenge with OVA. Values are expressed as mean $\pm S D$, ${ }^{*} p<0.05$ versus OVA-challenged group.
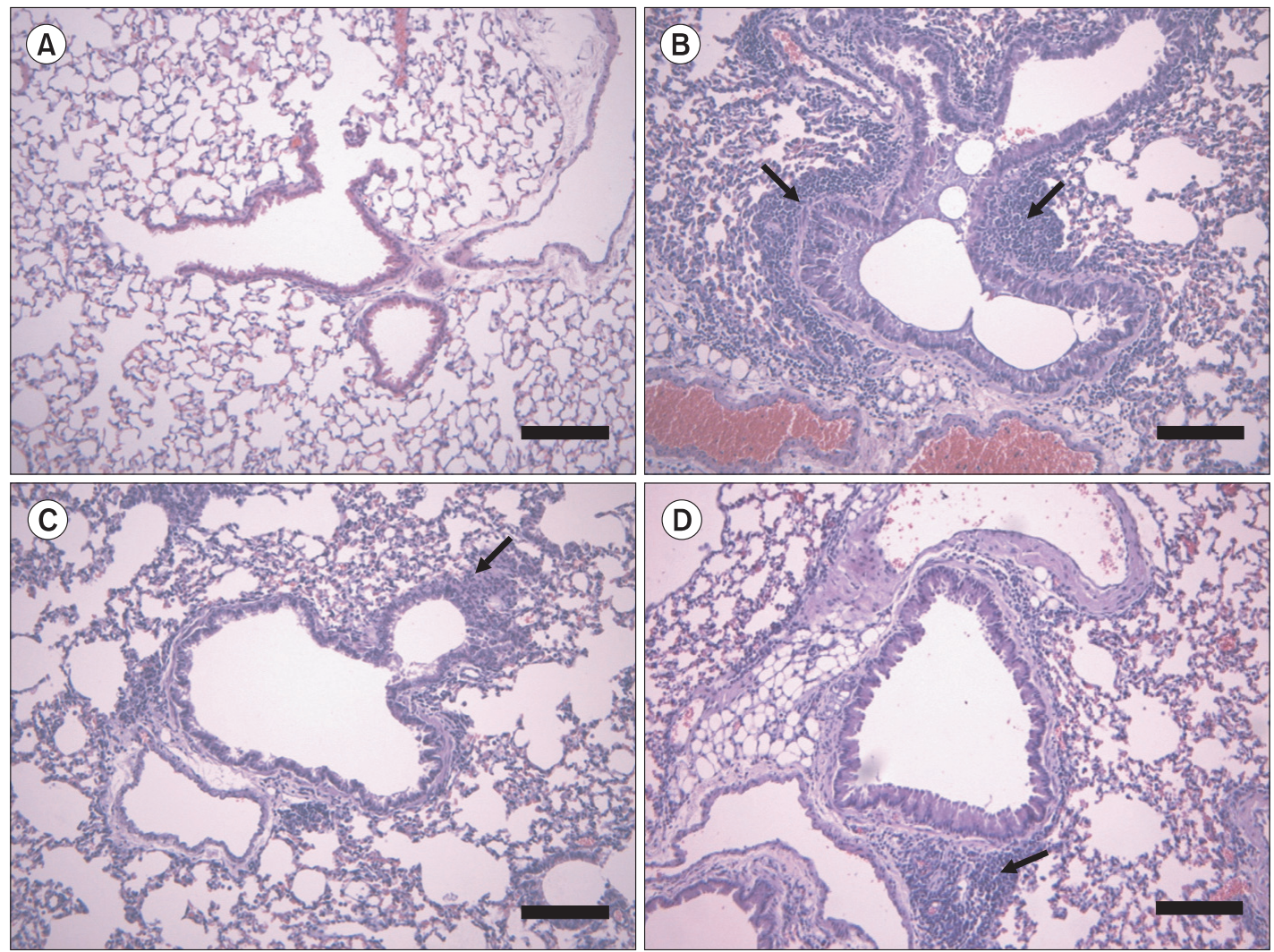

Fig. 2. Eosinophilia and airway remodeling in lung tissue. OVA mice showed severe infiltration of inflammatory cells (arrows) into the peribronchiole and perivascular tissue, but pre-treatment of A.suum before OVA-sensitization diminished these pathological changes. The SMX mice showed histopathologic changes those of allergic mice. (A) sham-sensitization and challenge with PBS group. (B) OVA-sensitization and challenge group. (C) A.suum extract treatment plus sensitization and challenge with OVA group. (D) Sulfamethoxazole (SMX) pretreated plus OVA-sensitization and challenge with OVA group. Bar=100 $\mu \mathrm{m}$. 

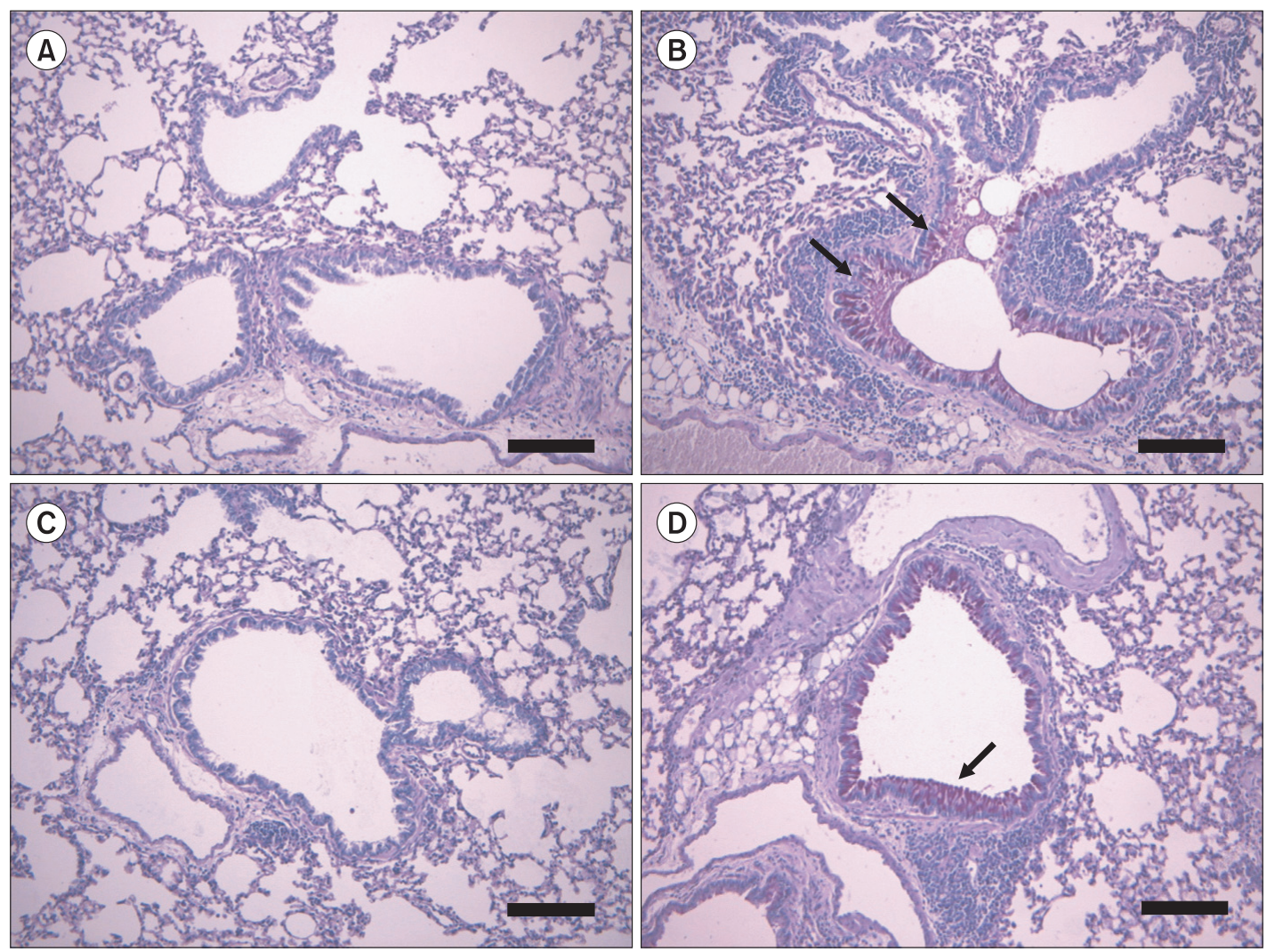

Fig. 3. Goblet cell hyperplasia and mucus production in lung tissue. The number of goblet cells (arrows) and mucus production were increased in the epithelium of allergic mice. Pre-treatment of A.suum decreased these changes significantly, while SMX did not. (A) shamsensitization and challenge with PBS group. (B) OVA-sensitization and challenge group. (C) A.suum extract treatment plus sensitization and challenge with OVA group. (D) Sulfamethoxazole (SMX) pre-treated plus OVA-sensitization and challenge with OVA group. Bar=100 $\mu \mathrm{m}$.
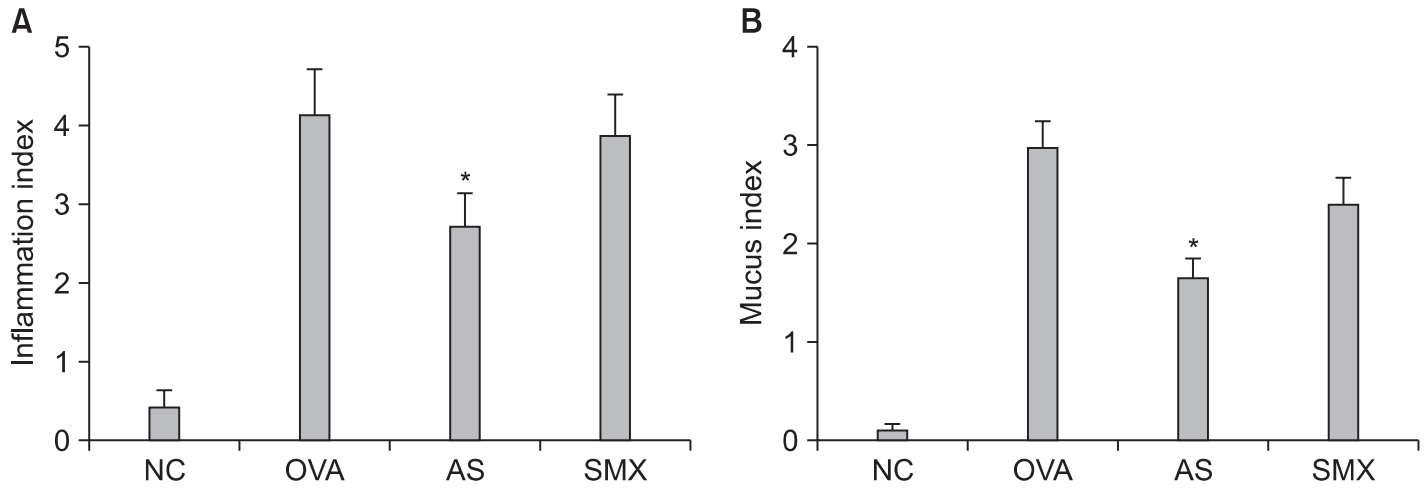

Fig. 4. Quantitative analysis of histopathologic changes. OVA mice obtained high scores in both the inflammation and mucus index compared with PBS-challenged mice. However, pre-treatment of A.suum before OVA-sensitization decreased both of the index, while SMX mice showed similar levels of histopathologic index compared with allergic mice. (A) Inflammation index. (B) Mucus index. NC: sham-sensitization and challenge with PBS, OVA: OVA-sensitization and challenge mice, AS: A.suum extract treatment plus sensitization and challenge with OVA, SMX: Sulfamethoxazole (SMX) pre-treated plus OVA-sensitization and challenge with OVA. Values are expressed as mean \pm SD. ${ }^{*} p<0.05$ versus OVA-challenged group. 

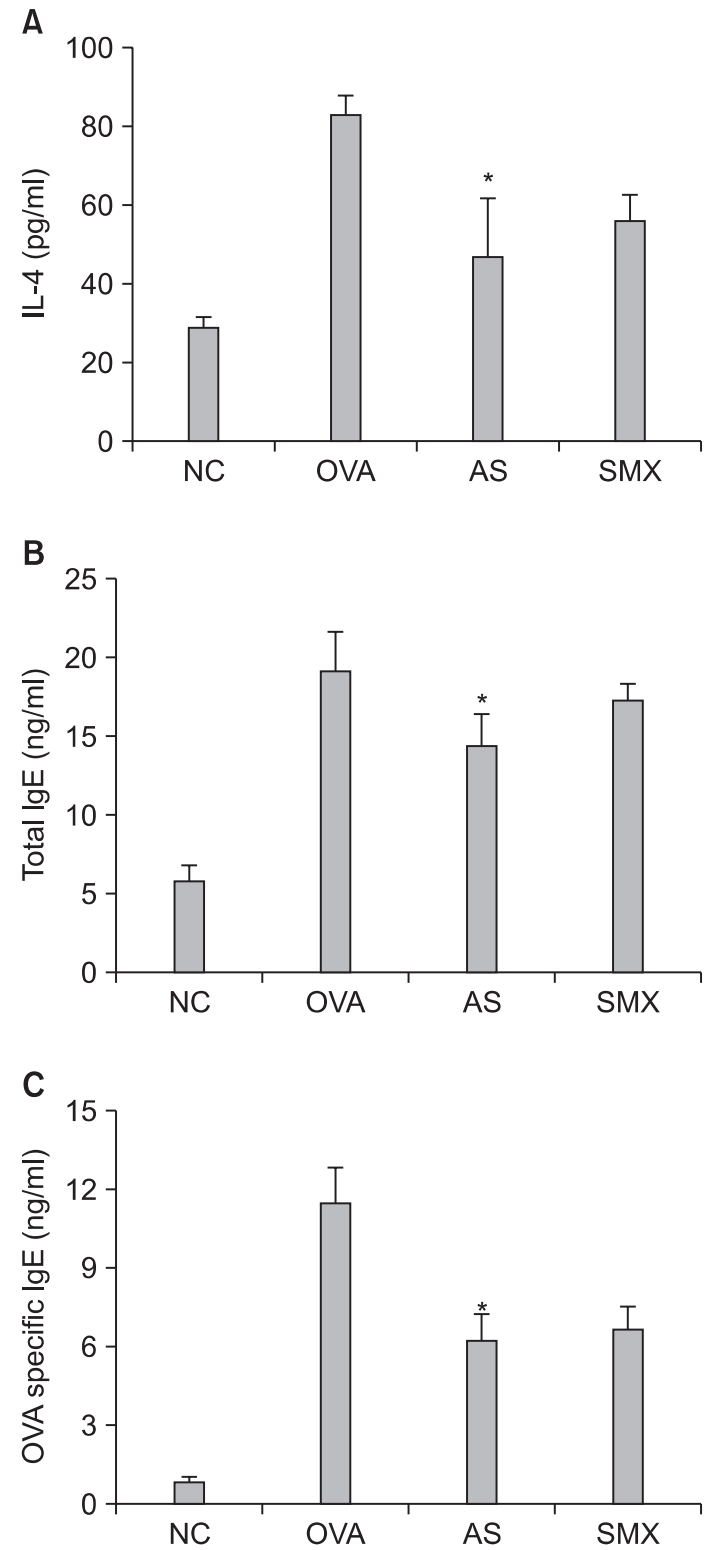

Fig. 5. IL-4 and total and OVA-specific IgE levels in BAL fluid. Pretreatment of A.suum extract before OVA sensitization diminished IL-4 and IgE levels while SMX did not show the significant change. (A) IL-4 level in BAL Fluid. (B) Total IgE level in BAL fluid. (C) OVAspecific IgE level in BAL fluid. NC: sham-sensitization and challenge with PBS, OVA: OVA-sensitization and challenge mice, AS: A.suum extract treatment plus sensitization and challenge with OVA, SMX: Sulfamethoxazole (SMX) pre-treated plus OVA-sensitization and challenge with OVA. Values are expressed as mean \pm SD. ${ }^{*} p<0.05$ versus OVA-challenged group.

animal (Fig. 5). This change diminished by immunizing with $A$. suum before OVA sensitization, but not by SMX.

\section{DISCUSSION}

Allergic asthma is a chronic inflammatory disease with a complex mechanism. The bronchoconstriction is initiated by mediators released from mast cells activated by allergen spe- cific IgE antibodies in the immediate phase. After this, the late phase reaction result in chronic and persistent obstruction by a severe eosinophilic inflammation in the lung. Elevated serum and BAL fluid IgE levels have been reported to be important in the development of asthmatic responses in human and OVA challenges induced more significant increase in the total serum IgE and BAL fluid IgE than asthmatic patients (Hamelmann et al., 1999; Holgate et al., 2005). Moreover, the Th2 cytokines, IL-4 and IL-5, were considered to associate with inflammatory cell infiltration and mucus hypersecretion and to regulate immune functions in mice (Steinke, 2004).

In the present study, OVA-sensitized and challenged mice showed classic signs of allergic airway disease, including increased inflammatory cell numbers in BAL fluid, histopathological features of perivascular and peribronchial inflammation, and increased IL-4 and IgE levels in BAL fluid. Immunizing by A. suum before OVA-sensitizing and challenging significantly reduced the release of Th2 cytokine and lgE levels compared with allergic mice. IL-4 induces mucus production through recruitment of Th2 cells to the lungs, and IL-4 and IL-13 are important in directing $B$ cell growth, differentiation, and secretion of IgE (Shimizu et al., 2003). Also histopathologic analyses assist that $A$. suum derivative inhibit eosinophilic inflammation in lung tissue. Previously, in studies with murine nematodes, such as Heligmosomoides polygyrus, have demonstrated that infection leads to strongly reduced OVA-induced eosinophilic airway inflammation (Wilson et al., 2005; Kitagaki et al., 2006). Consistently, Schistosoma mansoni infection decreases Th2type immune response to allergens in OVA-induced murine model (Mangan et al., 2006). These are elucidated both helminth infection and allergic asthma associate with Th2-type immune response and helminth regulate mechanisms associated with the Th2-type response (Foster, 1999). Isolated high molecular weight components obtained from $A$. suum body extract were responsible for its modulating effect on both Th-1 and Th-2 dependent immune response and suppression of the Th-1 associated parameters may related to high level expression of IL-4 and IL-10 (Faquim-Mauro EL and Macedo MS, 1998).

SMX, kind of sulfonamides that induced DRESS syndrome is associated with drug-induced immune thrombocytopenia in murine model (Bougie et al., 2010). SMX and its metabolites in a mouse model have been shown to allow quantitative and qualitative characterization of immune response provoked by different classes of chemical allergen. In addition, treatment of sulfasalazine associated eosinophilic peneumonia and skin rash (Timmer et al., 1992). Not a delayed-type hypersensitivity was induced by SMX and SMX-derivatized reactive metabolites in mice (Choquet-Kastylevsky et al., 2001) but also anaphylaxis or type I, IgE-mediated hypersensitivity reactions have been attributed to sulfonamides (Hemstreet and Page, 2006). BALB/c mice are known to respond sensitively to DNCB and DNP-BSA conjugate that induced eosinophilia and DTH reactions. However, in the present study, pre-treatment of SMX did not show modulatory effect in progress of allergic asthma by OVA-sensitization and challenge. Our result suggest that further studies are needed using other strains than BALB/C mice or higher dose of SMX and SMX metabolites conjugates to elucidate the modulating effects of sulfonamides and its derivatives on allergic inflammation which is concerned in dose response, exposure time, and other experimental asthma model. 
In conclusion, pre-treatment of A.summ derivative in mice sensitized and challenged with OVA decreased infiltration of inflammatory cells and mucus hypersecretion in lung, and significantly inhibited the increases in total inflammatory cells and eosinophils count, the levels of total and OVA-specific lgE and IL-4 in BAL fluid. However, SMX did not show modulatory effects on developing of asthma.

\section{ACKNOWLEDGMENTS}

This research was financially supported by research fund of Chungnam National University in 2010.

\section{REFERENCES}

Bougie, D. W., Nayak, D., Boylan, B., Newman, P. J. and Aster, R. H (2010) Drug-dependent clearance of human platelets in the NOD/ scid mouse by antibodies from patients with drug-induced immune thrombocytopenia. Blood. 116, 3033-3038.

Britton, J. (2003) Parasites, allergy, and asthma. Am. J. Respir. Crit Care. Med. 168, 266-267.

Callot, V., Roujeau, J. C., Bagot, M., Wechsler, J., Chosidow, O. Souteyrand, P., Morel, P., Dubertret, L., Avril, M. F. and Revuz, J. (1996) Drug-induced pseudolymphoma and hypersensitivity syndrome. Two different clinical entities. Arch. Dermatol. 132, 13151321

Choquet-Kastylevsky, G., Santolaria, N., Tedone, R., Aujoulat, M. and Descotes, J. (2001). Induction of delayed-type hypersensitivity to sulfamethoxazole in mice: role of metabolites. Toxicol. Lett. 119 183-192.

Elias, J. A., Zhu, Z., Chupp, G. and Homer, J. F. (1999) Airway remodeling in asthma. J. Clin. Invest. 104, 1001-1006.

Faquim-Mauro, E. L. and Macedo, M. S. (1998) The immunosuppressive activity of Ascaris suum is due to high molecular weight components. Clin. Exp. Immunol. 114, 245-251.

Foster, P. S. (1999) Allergic networks regulating eosinophilia. Am. J. Repair. Cell. Mol. Biol. 21, 451-454.

Hamada, K., Suzaki, Y., Goldman A., Ning, Y. Y., Goldsmith, C., Palecanda, A., Coull, B., Hubeau, C. and Kobzik, L. (2003) Allergen independent maternal transmission of asthma susceptibility. J. Immunol. 170, 5774-5780.

Hamelmann, E., Tadeda, K., Oshiba, A. and Gelfand, E. W. (1999) Role of $\lg \mathrm{E}$ in the development of allergic airway inflammation and airway hyperresponsiveness - a murine model. Allergy 54, 297-305.

Hemstreet, B. A. and Page, R. L. (2006) Sulfonamide allergies and outcomes related to use of potentially cross-reactive drugs in hospitalized patients. Pharmacotherapy 26, 551-557.

Hoffjan, S. and Ober, C. (2002) Present status on the genetic studies of asthma. Curr. Opin. Immunol. 14, 709-717.

Holgate, S. T. and Polosa, R. (2008) Treatment strategies for allergy and asthma. Nat. Rev. Immunol. 8, 218-230.

Holgate, S., Casale, T., Wenzel, S., Bousquet, J., Deniz, Y. and Reisner, C. (2005) The anti-inflammatory effects of omalizumab confirm the central role of IgE in allergic inflammation. J. Allergy. Clin. Immunol. 115, 459-465.

Kay, A. B. (1991) Asthma and inflammation. J. Allergy. Clin. Immumnol. 87, 893-910

Kitagaki, K., Businga, T. R., Racila, D., Elliott, D. E., Weinstock, J. V. and Kline, J. N. (2006) Intestinal helminths protect in a murine model of asthma. J. Immunol. 177, 1628-1635.

Lynch, N. R., Hagel, I., Perez, M., Di Prisco, M. C., Lopez, R. and Alvarez, N. (1993) Effect of anthelmintic treatment on the allergic reactivity of children in a tropical slum. J. Allergy. Clin. Immunol. 92, 404-411.

Mandell, G. L. and Sande, M. E. (1990) The phamacological basis of theraputics, eighth ed. Pergamon Press., New York.

Mangan, N. E., van Rooijen, N., McKenzie, A. N. and Fallon, P. G. (2006) Helminth-modified pulmonary immune response pretects mice from allergen-induced airway hyperresponsiveness. J. Immunol. 176, 138-147.

Matricardi, P. M. (2001) Prevalence of atopy and asthma in estern versus western Europe: why the difference? Ann. Allergy Asthma. Immunol. 87, 24-27.

Matricardi, P. M., Rosmoni, F., Riondino, S., Fortini, M., Ferrigno, L., Rapicetta, M. and Bonini, S. (2000) Exposure to food-borne and orofecal microbes versus airborne viruses in relation to atopy and allergic asthma: epidermiological study. BMJ. 320, 412-417.

McMillan, S. J., Xanthou, G. and Lloyd, C. M. (2005) Manipulation of allergen-induced airway remodeling by treatment with anti-TGFbeta antibody: effect on the Smad signaling pathway. J. Immunol. 174, 5774-5780.

Shimizu, T., Shimizu, S., Hattori, R. and Majina, Y. (2003) A mechanism of antigen-induced goblet cell degranulation in the nasal epithelium of sensitized rats. J. Allergy Clin. Immunol. 112, 119-125.

Soares, M. F., Mota, I. and Macedo, M. S. (1992) Isolation of Ascaris suum components which suppress IgE antibody response. Int. Arch. Allergy Immunol. 97, 37-43.

Steinke, J. W. (2004) Anti-interleukin-4 therapy. Immunol. Allergy. Clin. North. Am. 24, 599-614.

Strejan, G. and Campbell, D. H. (1967) Hypersensitivity to Ascaris antigens. I. Skin-sensitizing activity of serum fractions from guinea pigs sensitized to crude extracts. Immunol. 98, 893-900.

Timmer, R., Duurkens, V. A. and van Hees, P. A. (1992) Sulphasalazine-induced eosinophilic pneumonia. Neth. J. Med. 41, 153-157.

Van den Biggelaar, A. H., Van Ree, R., Rodrigues, L. C., Lell, B., Deelder, A. M., Kremsner, P. G. and Yazdanbakhsh, M. (2000) Decreased atopy in children infected with Schistosoma haematobium: a role for parasite-induced interleukin-10. Lancet. 356, 1723-1727.

Wilson, M. S., Taylor, M. D., Balic, A., Finney, C. A., Lamb, J. R. and Maizels, R. M. (2005). Suppression of allergic airway inflammation by helminth induced regulatory T cells. J. Exp. Med. 202, 11991212

Yemaneberhan, H., Bekele, Z., Venn, A., Lewis, S., Parry, E. and Britton, J. (1997) Prevalence of wheeze and asthma and relation to atopy in urban and rural Ethiopia. Lancet. 350, 85-90. 